\title{
Computational and experimental investigation of laminar flow mixing system in a pitched-blade turbine stirred tank
}

\author{
Yanyan Cuil ${ }^{1}$, Huabo Zhang ${ }^{1}$, Xiwen $\mathrm{Li}^{1}$, Mingjin Yang ${ }^{2}$, Zailin Guan ${ }^{1 *}$ \\ (1. State Key Laboratory of Digital Manufacturing Equipment and Technology, Huazhong University of Science and Technology, \\ Wuhan 430074, China; 2. College of Engineering and Technology, Southwest University, Chongqing 400715, China)
}

\begin{abstract}
The flow distribution and mixing performance of the laminar flow in the PBT impeller-stirred tank were investigated in this study. The variation along with mixing time of the flow distribution and concentration at the selected positions was visualized by means of the CFD and experiment methods. The CFD simulations results had a good agreement with the experimental results. In order to minish the Segregated Regions, the PBT impeller was optimally designed by means of orthogonal factorial experiment with selecting the $\theta_{99}$ mixing time as evaluation criteria. With the aim to increase the mixing efficiency, the optimal design results were obtained with the geometrical parameters of impeller diameter of $0.084 \mathrm{~m}$, discharge angle of $45^{\circ}$, blade width of $0.018 \mathrm{~m}$, and clearance of $0.05 \mathrm{~m}$, and the mixing time of the optimal impeller-stirred flow was about $180 \mathrm{~s}$, so this optimal design PBT impeller is more proper for the agricultural industries.
\end{abstract}

Keywords: mixing, laminar flow, PBT impeller, mixture homogeneity, CFD

DOI: $10.25165 /$ j.ijabe.20181104.2729

Citation: Cui Y Y, Zhang H B, Li X W, Yang M J, Guan Z L. Computational and experimental investigation of laminar flow mixing system in a pitched-blade turbine stirred tank. Int J Agric \& Biol Eng, 2018; 11(4): 111-117.

\section{Introduction}

Mixing process is widely used in chemical, biological, agricultural industries ${ }^{[1-3]}$. Increasing speed of the impeller can improve mixing efficiency, however, this method is inconvenient for shear-sensitive mixing media (such as fertilizer), so the laminar flow generally tends to occur ${ }^{[4,5]}$. In the laminar flow mixing system, Segregated Regions (SRs) act as major barriers to obtain good mixture homogeneity, so it is necessary to optimally design the mixing system geometry (including the blade's geometry) to minish the SRs ${ }^{[6-8]}$.

In the mixing operation, an optimal design or select of the stirring impeller with a suitable move mode is an effective way to eliminate the SRs in the laminar flow. In the mixing industry, pitched-blade turbine (PBT) impeller provides combination of both axial flow and radial flow, with characteristics of high shear level, simple design and easy cleanup ${ }^{[9,10]}$. To achieve the highest product quality and lowest production cost, mixing process efficiency and optimization are the main topics to be addressed ${ }^{[11]}$.

With the rapid development of computer science, Computational Fluid Dynamics (CFD) has been widely employed to help in predicting flow distribution and mixing performance, which greatly promotes advances of the mixing studies ${ }^{[12,13]}$. Takahashi et al. ${ }^{[14]}$ conducted CFD simulation to study impacts of

Received date: $2017-01-26 \quad$ Accepted date: $2017-12-20$

Biographies: Yanyan Cui, $\mathrm{PhD}$ candidate, research interests: production operations research, Email: cuiyanyan2011@hust.edu.cn; Huabo Zhang, MS, CFD simulation on mixing process, Email: 345787945@qq.com; Xiwen Li, PhD, Professor, mixing mechanism of the twin-blade planetary mixer, Email: xiwenli@hust.edu.cn; Mingjin Yang, PhD, CFD simulation and the mechanical structure design, Email: 853660331@qq.com.

*Corresponding author: Zailin Guan, PhD, Professor, research interests: advanced planning and production optimization. Intelligent manufacturing State Key Laboratory of Digital Manufacturing Equipment and Technology, Huazhong University of Science and Technology, Luoyu Street, Wuhan 430074, Hubei, China. Email: zlguan@hust.edu.cn. mixing paddles with different slopes on SRs and mixing time, without the investigation the blade's geometry. Qiao et al. ${ }^{[15]}$ studied effects of geometrical design and physical property on mixing quality of floating solids in the up-pumping PBT stirred tanks by using CFD technique qualitatively, didn't conduct the blade's optimal design. Alfaro-Ayala et al. ${ }^{[16]}$ just evaluated the optimal location of impellers on the central shaft in the down-pumping PBT stirred tanks by using combination techniques of CFD and Evolutionary Programming (EP).

For experimental technique, flow field visualization is an effective way to obtain qualitative and quantitative information about the flow pattern in the laminar flow. Bonnot et al. ${ }^{[17]}$ studied the impact of coaxial mixing paddle in co-rotating mode and counter-rotating mode on SRs and mixing time using acid-base neutralization experiment. Couerbe et al. ${ }^{[18]}$ studied the flow patterns of a carbopol solution in a stirred tank using Particle Image Velocimetry (PIV). Zadghaffari et al. ${ }^{[19]}$ conducted velocity measurement of liquid phase using PIV and concentration measurements of the determining tracer in the liquid phase using Planar Laser-induced Fluorescence (PLIF) technique.

The purpose of this study is to optimize the PBT impeller's geometry utilizing the CFD and experiment methods to improve the mixing efficiency. Three main objectives will be covered in this study. Initially, CFD simulation was used to visualize the flow distribution and concentration change at selected positions with time, and the visualization was compared with the experimental results. Secondly, orthogonal factorial experiment design technique based on Taguchi methodology was applied to evaluate effects of geometrical parameters of the PBT impeller on the mixing performance, and the optimal design of the PBT impeller was obtained. Finally, the mixing performance of the optimal design PBT impeller was validated experimentally.

\section{Materials and methods}

\subsection{Sample preparation}

Corn syrup and quartz sand were used as the mixing materials 
to constitute a 2-phase mixture. Corn syrup is the primary liquid phase with density $\rho_{\mathrm{l}}$ of $1394 \mathrm{~kg} / \mathrm{m}^{3}$ and dynamic viscosity $\mu$ of 3.0 Pa.s. Quartz sand is the secondary solid phase with density $\rho_{\mathrm{s}}$ of $2600 \mathrm{~kg} / \mathrm{m}^{3}$ and particle size $\varphi_{\mathrm{s}}$ of $0.3 \mathrm{~mm}$, and the volume fraction of the secondary phase $\alpha_{\mathrm{s}}$ is $1 \%$.

\subsection{Experimental setup}

The experimental vessel includes a standard configuration vertical, cylindrical, flat-bottomed tank with inner diameter $D$ $0.14 \mathrm{~m}$. The liquid level height $H$ is $0.14 \mathrm{~m}$. An evenly spaced, concentric, four-blade PBT impeller with rotating speed $N 300$ rpm, and the mixer is selected as DRAGONLAB OS40-S, as shown in Figure 1 . The impeller is driven by a direct current motor with maximum power output $100 \mathrm{~W}$. The original impeller has dimensions for the flow visualization as follows: impeller diameter $d 0.07 \mathrm{~m}$, shaft diameter $D_{\mathrm{sh}} 0.008 \mathrm{~m}$, blade width $b 0.018 \mathrm{~m}$, discharge angle $\theta 45^{\circ}$, and clearance $C 0.04 \mathrm{~m}$. According to the definition of $R e$ number $\left(R e=\rho_{1} N d^{2} /(60 \mu)\right)$, the current mixing system $R e=45.5$. When $R e$ is less than 2300, laminar flow occurs $^{[20]}$.
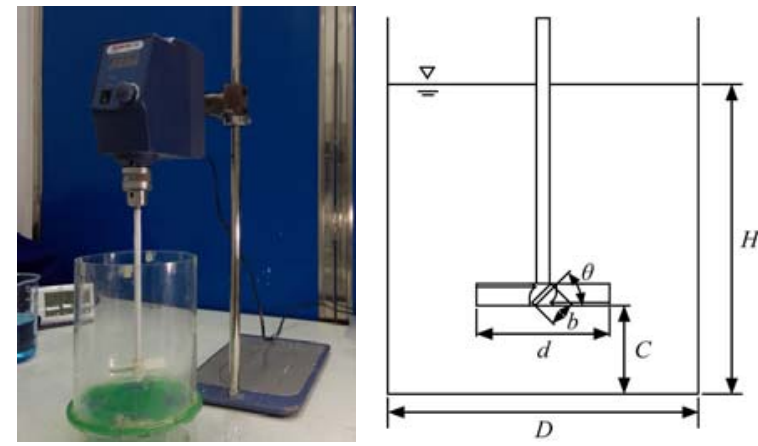

Figure 1 Experimental setup of the four-blade PBT impeller mixer

To evaluate the laminar flow mixing process in the stirred tank, the front photographic images of the entire tank were taken at the selected moment using a professional digital camera (Canon 500D), and special care was taken to maintain the illumination quality and the camera positions for all images. To obtain concentration of the mixing slurry, slurry samples of $1.0 \mathrm{~mL}$ were taken using a syringe at fixed sampling position, as shown in Figure 2. Solid particles in all samples were numbered manually, and the variation of solid particles' number indicated the concentration change of the laminar flow in the stirred tank. The sampling intervals from 0$60 \mathrm{~s}$ and $60-360 \mathrm{~s}$ were $10 \mathrm{~s}$ and $30 \mathrm{~s}$, respectively.
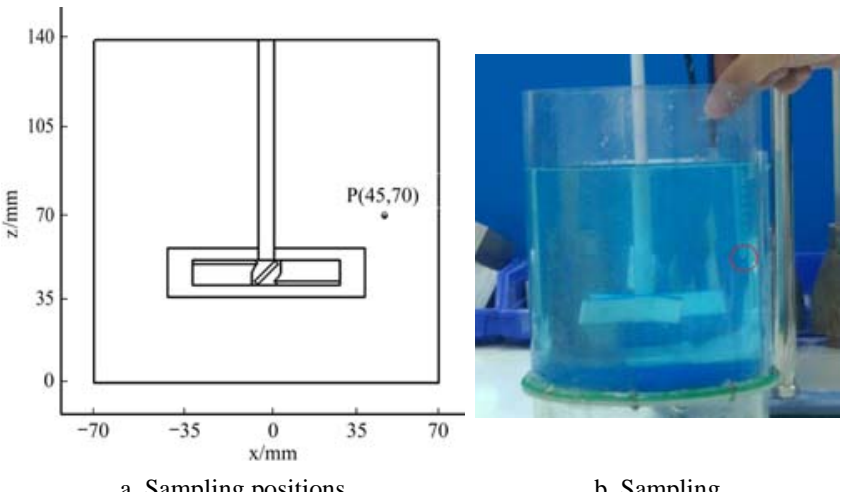

a. Sampling positions

b. Sampling

Figure 2 Sampling point inside mixing vessel of the particle concentration

\subsection{CFD simulation}

Eulerian model was adopted for the CFD simulation. The multiphase flow is described as interpenetrating continua incorporating concept of volume fractions of each phase, denoted by $\alpha$, and laws of conservation of mass and momentum are satisfied by each phase individually ${ }^{[21]}$. The conservation equations pertaining to the liquid (continuous) phase are given as follows (without considering mass transfer) ${ }^{[15]}$.

$$
\begin{gathered}
\frac{\partial}{\partial t}\left(\alpha_{1} \rho_{1}\right)+\nabla \cdot\left(\alpha_{1} \rho_{1} \mathbf{u}_{1}\right)=0 \\
\frac{\partial}{\partial t}\left(\alpha_{1} \rho_{1} \mathbf{u}_{1}\right)+\nabla \cdot\left(\alpha_{1} \rho_{1} \mathbf{u}_{1} \mathbf{u}_{1}\right)=-\alpha_{1} \nabla p+\nabla \cdot\left(\overline{\overline{\tau_{1}}}\right)+\alpha_{1} \rho_{1} \boldsymbol{g}+\boldsymbol{F}_{1}
\end{gathered}
$$

Continuity and momentum equations for the solid (dispersed) phase are exactly the same and thus are not presented here.

The software ICEM and Fluent were used to draw the geometry of stirred tank and to process the data for flow distribution and concentration, respectively. As large aspect ratios and sharp element angles exist on the impeller and the region surrounding it, so the fluid flow is terribly complex in this region. Unstructured mesh scheme, identified by irregular connectivity, has better convenience and adaptability than structured mesh scheme to deal with irregular shape geometry ${ }^{[22]}$. The fluid zone in the stirred tank is divided into two parts: one is the inner rotating zone, namely the impeller and the region surrounding it, the other is the outer non-rotating zone, as shown in Figure 3. An interface is introduced for exchanging parameters in the governing equations of liquid and solid particles between the inner and outer zones. Multiple Reference Frame (MRF) approach is employed to model the problem that involves both stationary and moving zones as it provides accurate prediction and demands less computational resource $^{[23]}$. The rotating reference frame is for the inner zone, and the stationary frame is for the outer zone. Tetrahedron cells were automatically generated by means of robust mesh method, with mesh size of $2 \mathrm{~mm}$ on the impeller, $2.5 \mathrm{~mm}$ at the interface, and $5 \mathrm{~mm}$ for the global domain. The computational cells consisted of 685662 tetrahedrons.

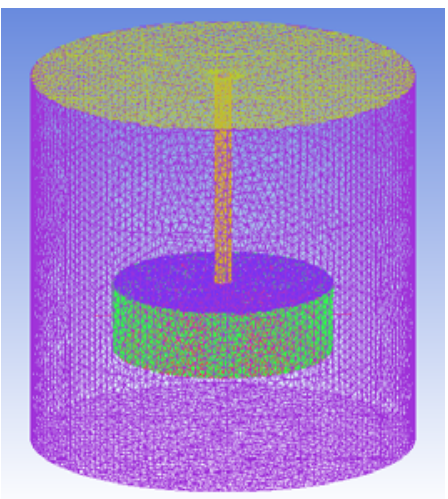

Figure 3 Mesh model of the four-blade PBT mixer

For the CFD simulation, Laminar Viscous Model was adopted. The second order upwind was used for the spatial discretization, and the pressure-velocity coupling was computed with the SIMPLE (Semi-Implicit Method for Pressure Linked Equations) scheme. The boundary conditions of wall function were defined as follows: moving wall at the interface and impeller shaft, with absolute rotational motion $-300 \mathrm{r} / \mathrm{min}$; moving wall on the turbine surface of the impeller, with relative motion to adjacent cell zone; stationary wall for others. The secondary phase of solid particles with volume fraction $1 \%$ was patched to cell zone at the top of the domain.

Mixing time generally refers to the time required for achieving a predefined level of homogeneity of a flow tracer in a mixing vessel. It is a key parameter for analyzing the performance and 
the hydrodynamics of a mixing system ${ }^{[24]}$. Levels of homogeneity such $90 \%, 95 \%$, and $99 \%$ of the final concentration are common in the literature, and the corresponding mixing time terms are labeled as $\theta_{90}, \theta_{95}$ and $\theta_{99}$, respectively ${ }^{[16]}$. In this study, $99 \%$ mixing time $\theta_{99}$ was used to analyze the performance and the hydrodynamics of the flow in the stirred tank. Three points were selected as monitoring positions for the solid particle concentration, as shown in Figure 4. The mixing time of the flow system is defined as the maximum value of mixing time at the three points, with a concentration deviation less than $5 \%$.

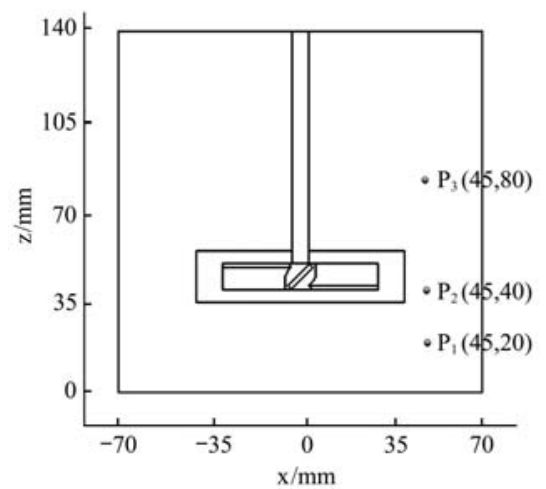

Figure 4 Monitoring positions inside mixing vessel of particle concentration

Orthogonal factorial experimental design technique based on Taguchi methodology was applied to evaluate effects of geometrical parameters of the PBT impeller on the mixing time. For the orthogonal factorial experimental design, the dimensionless number $C_{e}$ is defined as:

$$
C_{e}=\theta_{95}^{2} \cdot P_{V} / \eta=\frac{\theta_{95}^{2} M_{\omega}}{V \eta}=C_{e}^{\prime} \cdot \frac{\omega}{V \eta}
$$

where, $P_{V}$ is mixing energy of unit volume, $\mathrm{W} / \mathrm{m}^{3} ; \theta_{95}$ is mixing time, $\mathrm{s} ; \eta$ is viscosity of mixing materials, $\mathrm{Pa} \cdot \mathrm{s} ; M$ is torque, $\mathrm{N} \cdot \mathrm{m}$; $V$ is volume, $\mathrm{m}^{3} ; \omega$ is angular velocity, $\mathrm{rad} / \mathrm{s}$.

Main control factors affecting the mixing time were defined as: factor A: discharge angle of the impeller; factor B: impeller's diameter; factor C: blade width of the impeller; factor D: clearance. Levels of each control factors were shown in Table 1. Experiments were designed in accordance with appropriate orthogonal array $\mathrm{L}_{16}\left(4^{5}\right)$, a 4-level 5-factor array with 16 runs, and their arrangements were shown in Table 2. The results of mixing time values were obtained by means of CFD simulation for the statistical analyses of range and variance.

Combination of different control factors' levels with the lowest value of mixing time, and combination with the highest value within the 16 runs will be available after the CFD simulations. The former is simplified as good comb., and the latter is simplified as bad comb.

Range analysis of orthogonal factorial experiment result of mixing time gives qualitative evaluation of main factors that affect mixing efficiency, and the analysis of variance gives quantitative evaluation of the control factors. The optimal levels of each control factor and the optimal combination of levels of all control factors can be also obtained by means of range analysis. The optimal combination is simplified as optimal comb.

Then, three combinations can be obtained, namely, the good comb., the bad comb., and the optimal comb. Consequently, for the purpose of concentration validation of the laminar flow in the stirred tank, three PBT impellers with geometrical parameters determined by these combinations were manufactured using a 3-D printer. The material of the impellers was Acrylonitrile Butadiene Styrene. The particle concentration is indirectly measured through the number change of solid particle with time as mentioned above (see Figure 4).

Table 1 Levels of each control factors

\begin{tabular}{ccccc}
\hline Level & Factor $\mathrm{A} /\left(^{\circ}\right)$ & Factor $\mathrm{B} / \mathrm{m}$ & Factor $\mathrm{C} / \mathrm{m}$ & Factor $\mathrm{D} / \mathrm{m}$ \\
\hline 1 & 30 & 48 & 12 & 20 \\
2 & 45 & 60 & 15 & 30 \\
3 & 60 & 70 & 18 & 40 \\
4 & 75 & 84 & 20 & 50 \\
\hline
\end{tabular}

Table 2 Experiment arrangements and values of mixing time

\begin{tabular}{ccccccc}
\hline No. & Factor A & Factor B & Factor C & Blank column & Factor D & Mixing time $\theta_{99} / \mathrm{s}$ \\
\hline 1 & 1 & 1 & 1 & 1 & 1 & 362 \\
2 & 1 & 2 & 2 & 2 & 2 & 318 \\
3 & 1 & 3 & 3 & 3 & 3 & 264 \\
4 & 1 & 4 & 4 & 4 & 4 & 188 \\
5 & 2 & 1 & 2 & 3 & 4 & 290 \\
6 & 2 & 2 & 1 & 4 & 3 & 316 \\
7 & 2 & 3 & 4 & 1 & 2 & 286 \\
8 & 2 & 4 & 3 & 2 & 1 & 180 \\
9 & 3 & 1 & 3 & 4 & 2 & 344 \\
10 & 3 & 2 & 4 & 3 & 1 & 324 \\
11 & 3 & 3 & 1 & 2 & 4 & 312 \\
12 & 3 & 4 & 2 & 1 & 3 & 260 \\
13 & 4 & 1 & 4 & 2 & 3 & 364 \\
14 & 4 & 2 & 3 & 1 & 4 & 282 \\
15 & 4 & 3 & 2 & 4 & 1 & 384 \\
16 & 4 & 4 & 1 & 3 & 2 & 366 \\
\hline
\end{tabular}

\section{Results and discussion}

\subsection{Mixing flow pattern}

Figure 5 shows the flow pattern comparison between CFD simulations and the experimental for the original PBT impeller-stirred laminar system. Figure 6 shows the velocity distribution in different planes of the laminar flow.

Initially, solid particles on the top of corn syrup move downward along with a circle region parallel to the shaft wall of the PBT impeller (the circle region having a certain distance off the shaft wall), since this region has a high magnitude of velocity compared with its neighbor regions, as shown in flow pattern at $10 \mathrm{~s}$ in Figure 5 and velocity magnitude in Figure 6d. As the solid particles reach region of turning blades, they are pumped outside by the blades and divided into two parts near wall of the stirred tank: one moving up, and the other moving down, as shown in flow pattern at $60 \mathrm{~s}$ in Figure 5 and velocity magnitude in Figure 6a and Figure 6b. As time increases, a toroidal region is clearly visible above the impeller, marked by circles, as shown in flow pattern at $180 \mathrm{~s}$ in Figure 5. The segregated region (SR) remains apart from the rest of the system, and it is difficult to mix well in this region. In the same period, a pumping cone is visible below the impeller, marked by a triangle in the figure, and it is formed by the comprehensive function of complex velocity distribution in this region, as shown in Figure $6 \mathrm{~b}$ and Figure 6c. Since SRs act as major barriers to obtain good mixture homogeneity, it takes quite a long time to destroy the SRs in the laminar flow to finally obtain the homogeneous mixture slurry, as shown in flow pattern at $360 \mathrm{~s}$ in Figure 5. 


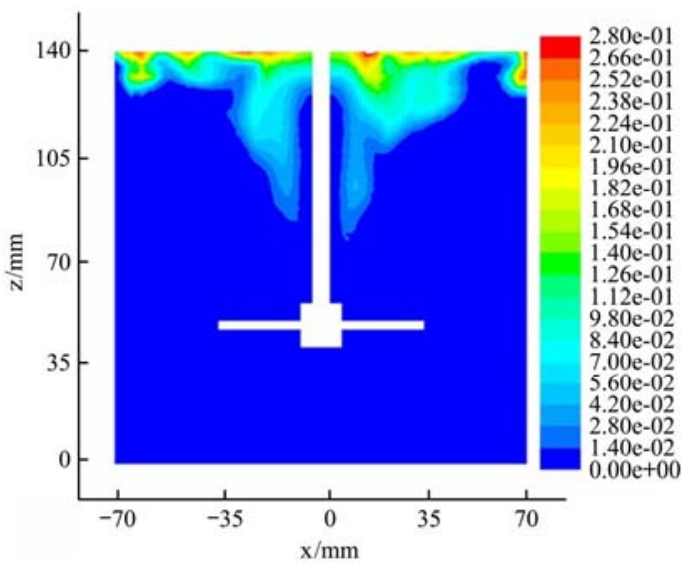

a1. CFD simulation at $10 \mathrm{~s}$

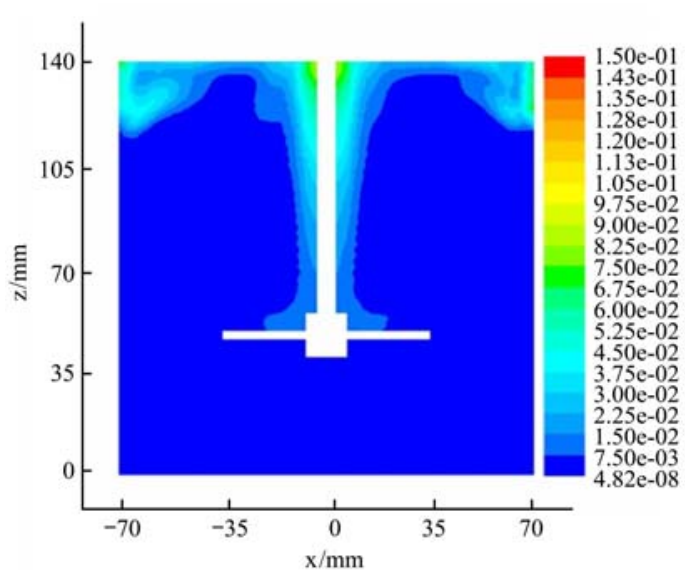

a2. CFD simulation at $60 \mathrm{~s}$

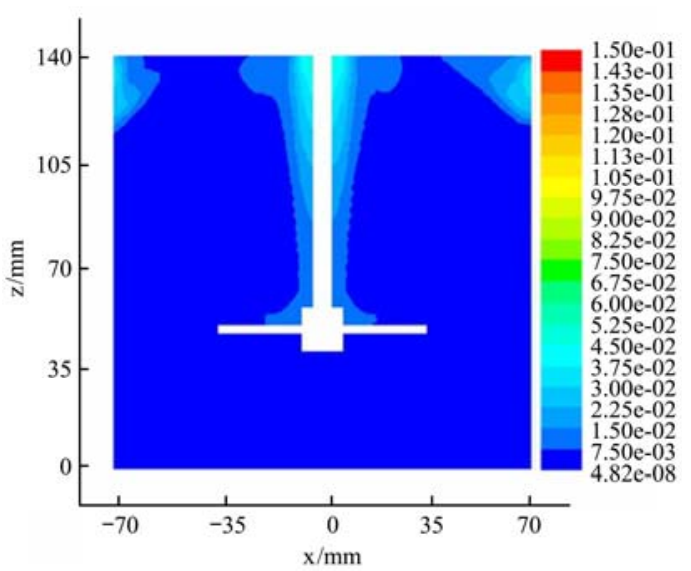

a3. CFD simulation at $180 \mathrm{~s}$

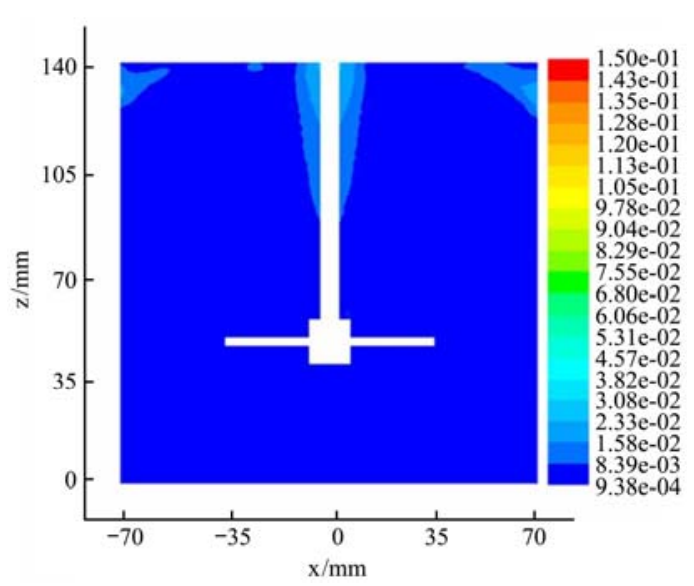

a4. CFD simulation at $360 \mathrm{~s}$

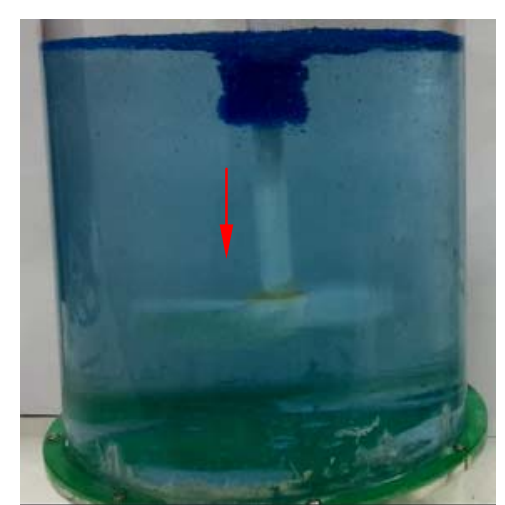

b1. Experiment at $10 \mathrm{~s}$

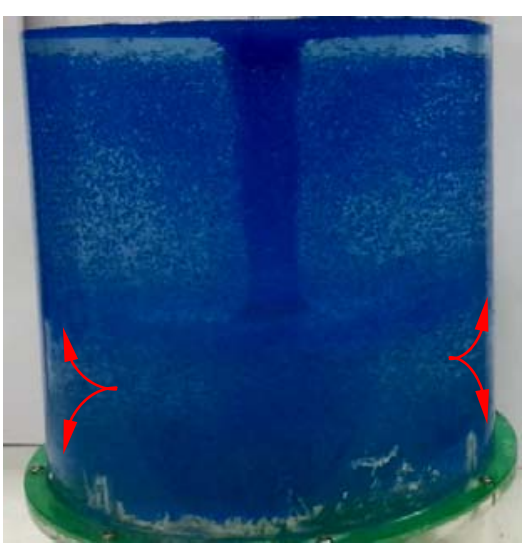

b3. Experiment at $60 \mathrm{~s}$

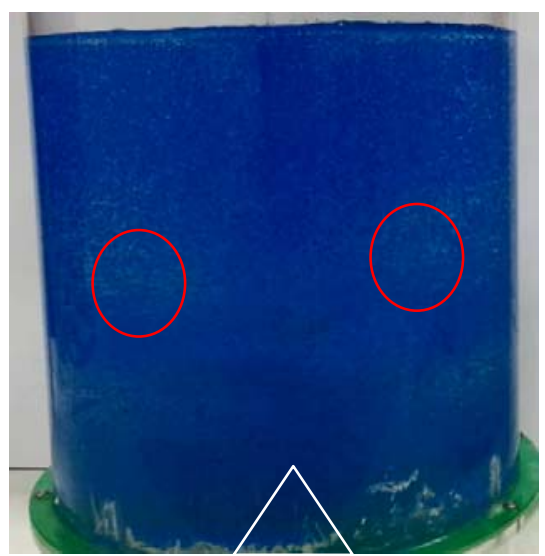

b3. Experiment at $180 \mathrm{~s}$

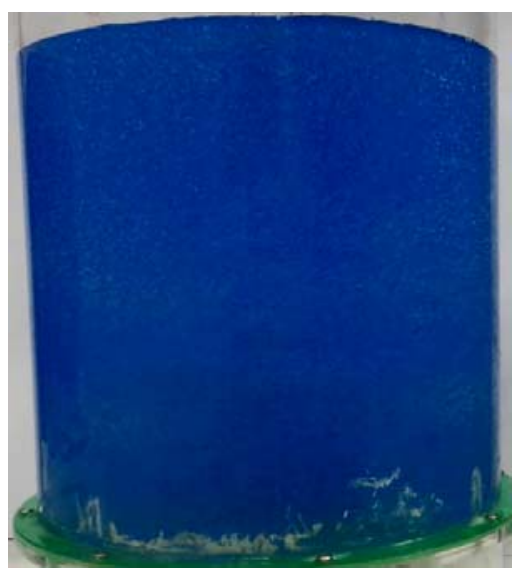

b4. Experiment at $360 \mathrm{~s}$ 


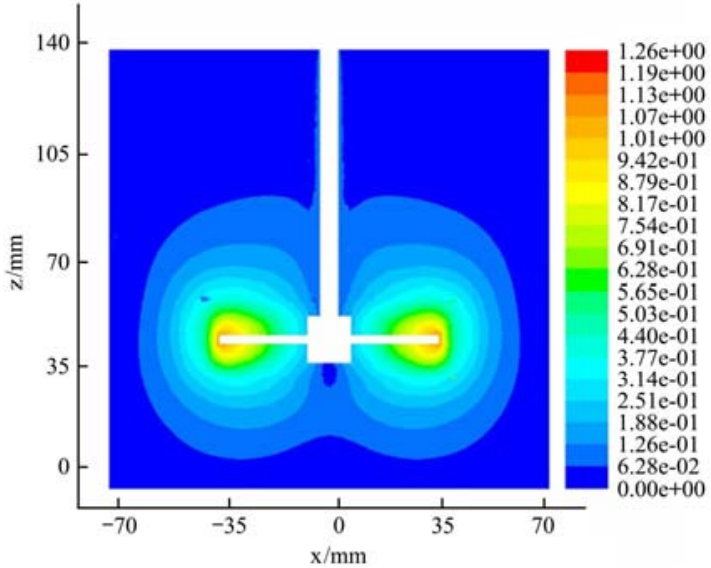

a. Velocity contour in the vertical plane

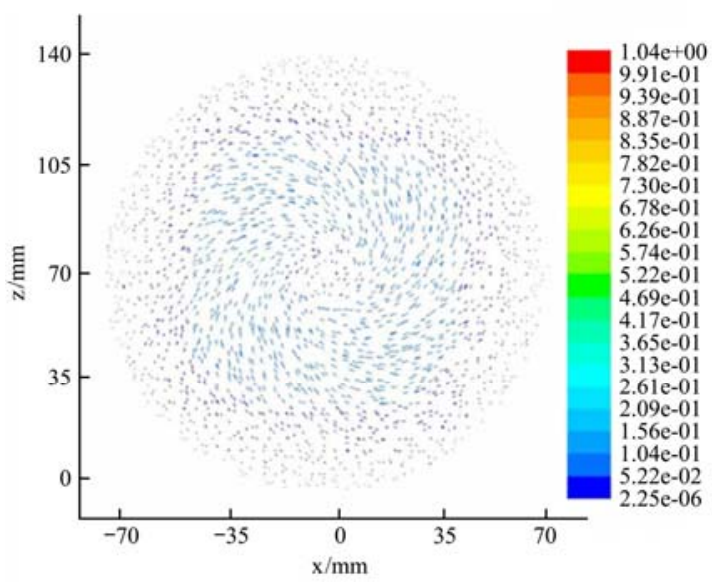

c. Velocity magnitude in the plane of $z 10 \mathrm{~mm}$

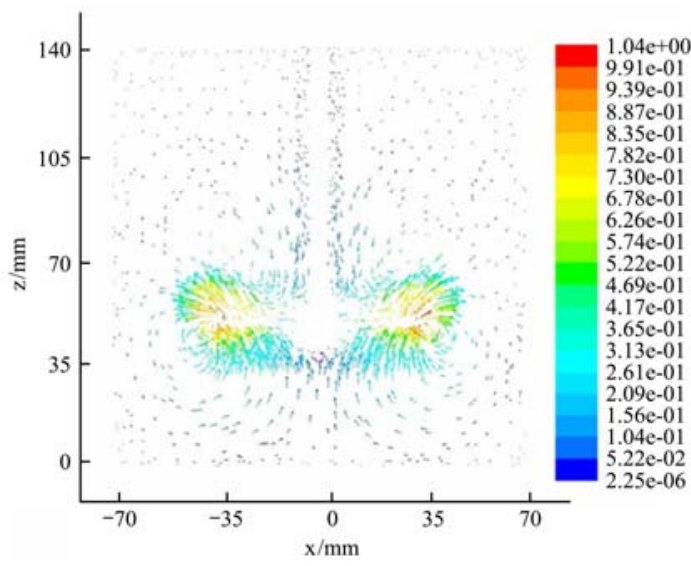

b. Velocity magnitude in the vertical plane

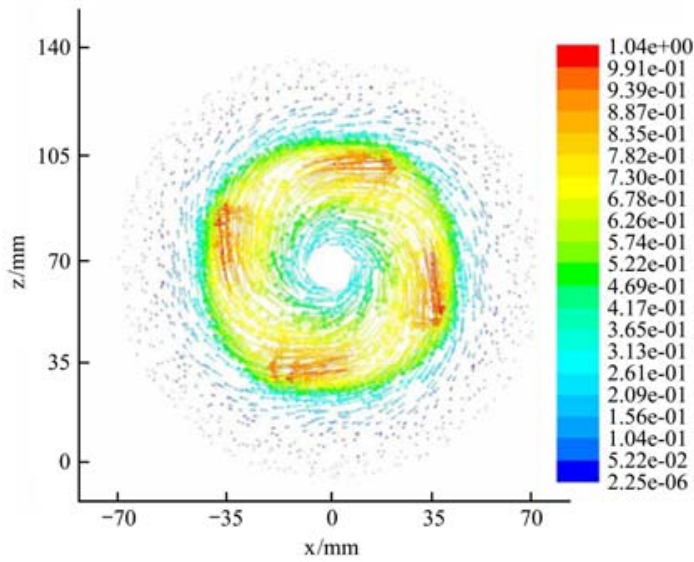

d. Velocity magnitude in the plane of $z 50 \mathrm{~mm}$

Figure 6 Velocity distribution

\subsection{Mixing performance and impeller optimization}

According to the experiment arrangements and the corresponding levels of geometrical parameters of each control factor, CFD simulations of laminar flow mixing were conducted to obtain the values of mixing time $\theta_{99}$ for each experiment run, as shown in Table 2.

Statistical analyses of range and variance were performed to obtain the impacts and their significance of each factor on mixing time. Range analysis results were shown in Table 3. Results of the variance analysis were shown in Table 4 . The blank column of the orthogonal array was treated as error column in the statistical analyses.

For the range analysis, the values in the cells of each level of the control factors in Table 3 represent the mean mixing time of the corresponding levels and factors. The delta values of each factor indicate the biggest change of mean mixing time of the factor, namely the impact on the mean mixing time. The numbers in the cells of rank row which indicate control factor has more impact on mixing time. Range analysis show that: factor B has the most impact on mixing time, and it is followed by factor $\mathrm{A}$ and factor $\mathrm{C}$ sequentially, and the factor $\mathrm{D}$ has the least impact.

For the analysis of variance, an appropriately formed F-ratio was computed for each control factor, and it was compared to a critical value corresponding to a certain pre-selected probability, namely critical F-ratio, that the observed "impacts" are purely due to chance. The analysis results show that there is a same impact order of significance as range analysis. The star mark “*” in Table 4 indicates a $95 \%$ probability that factors A to D are purely due to chance. To be exact, the probabilities are $98.4 \%, 98 \%$,
$97 \%$ and $95.1 \%$ for controls B, A, C and D, respectively ${ }^{[25]}$.

From the statistical analyses of mixing time, the optimal combination of geometrical parameters of the PBT impeller was obtained by selecting the level of each control factor with the lowest mean mixing time in Table 3 , and it is $\mathrm{A}_{2} \mathrm{~B}_{4} \mathrm{C}_{3} \mathrm{D}_{4}$ with parameters as follows: impeller diameter $0.084 \mathrm{~m}$, discharge angle $45^{\circ}$, blade width $0.018 \mathrm{~m}$, and clearance $0.05 \mathrm{~m}$. The good combination is of run No. 8, and the bad combination is of run No. 15 , with the lowest mixing time and the highest mixing time, respectively.

Table 3 Range analysis of mixing time

\begin{tabular}{cccccc}
\hline Level & Factor A & Factor B & Factor C & Blank column & Factor D \\
\hline 1 & 283 & 340 & 339 & 297.5 & 312.5 \\
2 & 268 & 310 & 313 & 293.5 & 328.5 \\
3 & 310 & 311.5 & 267.5 & 311 & 301 \\
4 & 349 & 248.5 & 290.5 & 308 & 268 \\
Delta & 81 & 91.5 & 71.5 & 17.5 & 60.5 \\
Rank & 2 & 1 & 3 & Error & 4 \\
\hline
\end{tabular}

Table 4 Analysis of variance of mixing time

\begin{tabular}{cccccc}
\hline $\begin{array}{c}\text { Source of } \\
\text { variance }\end{array}$ & $\begin{array}{c}\text { Degrees of } \\
\text { freedom }\end{array}$ & $\begin{array}{c}\text { Sum of } \\
\text { squares }\end{array}$ & $\begin{array}{c}\text { Mean sum } \\
\text { of squares }\end{array}$ & $F$-ratio & Critical $F$-ratio \\
\hline A & 3 & 15156 & 5052 & $18.17^{*}$ & \\
B & 3 & 17838 & 5946 & $21.39^{*}$ & \\
C & 3 & 11246 & 3748.7 & $13.48^{*}$ & \\
Blank column & 3 & 834 & 278 & Error & $F_{0.05}(3,3)=9.28$ \\
D & 3 & 7874 & 2624.7 & $9.44^{*}$ & $F_{0.01}(3,3)=29.46$ \\
Total & 15 & 52948 & & & \\
\hline
\end{tabular}




\subsection{Concentration validation}

The PBT impellers with parameters of the aforementioned combinations were manufactured using a 3-D printer using material Acrylonitrile Butadiene Styrene. The mixing experiments were conducted for these impellers, and the samples of mixing slurry were taken using a syringe for solid particle numbering to obtain the concentration change of the laminar flow indirectly. Figure 7 shows the samples of slurry by impeller of the optimal combination. Figure 8 shows curves of solid particle number with time.

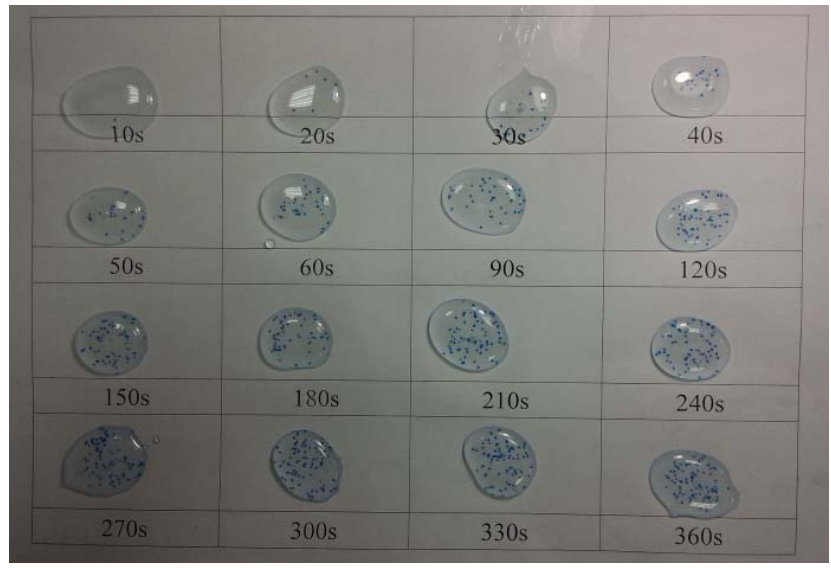

Figure 7 Samples of slurry by impeller of the optimal combination

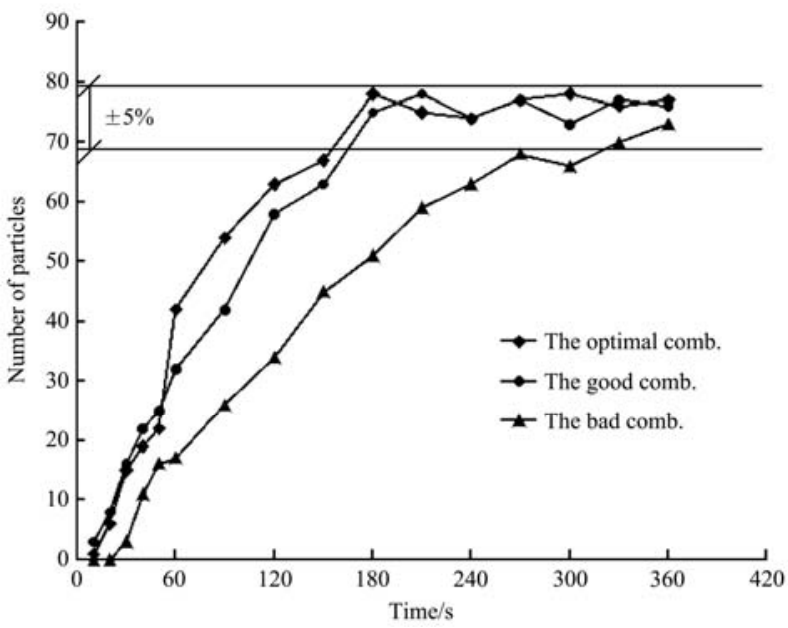

Figure 8 Curves of solid particle number with time

As shown in Figure 8, values of solid particle number of the three impeller-stirred laminar systems increase with time. The optimal combination is the first that reaches the $\pm 5 \%$ deviation range of solid particle number, and it is followed by the good combination and bad combination sequentially, with bad combination lagging behind quite a lot. The mixing time $\theta_{99}$ is about $180 \mathrm{~s}$ for the optimal combination and good combination impeller-stirred laminar systems.

Compared with the good combination of impeller-stirred laminar system, the optimal combination slightly decreases the mixing time. The difference of these two combinations is the level of control factor $\mathrm{D}$, and factor $\mathrm{D}$ has the least impact among factors $\mathrm{A}$ to $\mathrm{D}$ on the mixing time. As a result, the mixing performance of the good combination impeller is close to that of the optimal combination impeller, which coincides with the CFD simulation and orthogonal factorial experiment result.

\section{Conclusions}

The computational and experimental investigation of laminar system in a PBT impeller-stirred tank was carried out in this study. The main conclusions are drawn as follows:

1) For the PBT impeller-stirred tank, the CFD simulations results have good agreement with experiments. Segregated Regions were obviously viewed in the laminar flow space of the PBT impeller-stirred tank, and each segregated region has a different flow pattern and is functioning differently for the flow mixing.

2) Control factor of impeller diameter of the PBT impeller has the most impact on mixing time, and it is followed by factors of discharge angle and blade width sequentially, and factor of clearance has the least impact, with probabilities of $98.4 \%$, 98\%, $97 \%$, and $95.1 \%$, respectively, that these factors are purely due to chance.

3) The optimal combination of geometrical parameters of the PBT impeller has parameters of impeller diameter $0.084 \mathrm{~m}$, discharge angle $45^{\circ}$, blade width $0.018 \mathrm{~m}$, and clearance $0.05 \mathrm{~m}$, and the mixing time $\theta_{99}$ for the laminar system is about $180 \mathrm{~s}$.

\section{Acknowledgements}

This study was financially supported by the National Special Fund Program for Major Scientific Instruments and Equipment Development (2011YQ160002) and Open Research Fund Program of Hubei Provincial Key Laboratory of Chemical Equipment Intensification and Intrinsic Safety (2015KA03).

\section{[References]}

[1] Aubin J, Xuereb C. Design of multiple impeller stirred tanks for the mixing of highly viscous fluids using CFD. Chemical Engineering Science, 2006; 61(9): 2913-20.

[2] Brun T, Rabuske J E, Todero I, Almeida T C, Junior J J D, Ariotti G, et al Production of bioherbicide by Phoma sp in a stirred-tank bioreactor. 3 Biotech, 2016; 6: 230.

[3] Jitrwung R, Yargeau V. Biohydrogen and Bioethanol Production from Biodiesel-Based Glycerol by Enterobacter aerogenes in a Continuous Stir Tank Reactor. International Journal of Molecular Sciences, 2015; 16(5): 10650-10664.

[4] TAKAHASHI K, MOTODA M. Chaotic mixing created by object inserted in a vessel agitated by an impeller. Chemical Engineering Research \& Design, 2009; 87(4A): 386-390.

[5] Xiao X, Yu L, Xie F, Bao X, Liu H, Ji Z, et al. One-step method to prepare starch-based superabsorbent polymer for slow release of fertilizer. Chemical Engineering Journal, 2017; 309: 607-616.

[6] Lamberto D J, Muzzio F J, Swanson P D. Using time-dependent RPM to enhance mixing in stirred vessels. Chemical Engineering Science, 1996; 51(5): 733-741.

[7] Dong L, Johansen S, Engh T. Flow induced by an impeller in an unbaffled tank-I. Experimental. Chemical Engineering Science, 1994; 49(4): 549-60.

[8] Zalc J M, Szalai E S, Alvarez M M, Muzzio F J. Using CFD to understand chaotic mixing in laminar stirred tanks. Aiche Journal, 2002; 48(10): 2124-2134.

[9] Kamla Y, Bouzit M, Hadjeb A, Arab I M, Beloudane M. CFD study of the effect of baffles on the energy consumption and the flow structure in a vessel stirred by a Rushton turbine. Mechanika, 2016; 3: 190-197.

[10] Hashemi N, Ein-Mozaffari F, Upreti S R, Hwang D K. Analysis of power consumption and gas holdup distribution for an aerated reactor equipped with a coaxial mixer: Novel correlations for the gas flow number and gassed power. Chemical Engineering Science, 2016; 151: 25-35.

[11] Zadghaffari R, Moghaddas J S, Revstedt J. Large-eddy simulation of turbulent flow in a stirred tank driven by a Rushton turbine. Computers \& Fluids, 2010: 39(7): 1183-1190.

[12] Montante G, Micale G, Magelli F, Brucato A. Experiments and CFD Predictions of Solid Particle Distribution in a Vessel Agitated with Four Pitched Blade Turbines. Chemical Engineering Research and Design, 2001; 79(8): 1005-1010.

[13] Zhang J, Li X, He R, Liang J. Study on double-shaft mixing paddle 
undergoing planetary motion in the laminar flow mixing system. Advances in Mechanical Engineering, 2015; 7(7): 1-12.

[14] Takahashi K, Sugo Y, Takahata Y, Sekine H, Nakamura M. Laminar mixing in stirred tank agitated by an impeller inclined. International Journal of Chemical Engineering, 2012; 2012: 1-10.

[15] Qiao S, Wang R, Yan Y, Yang X X. Computational fluid dynamics analysis to effects of geometrical design and physical property on complete suspension of floating solids in stirred tanks. Asia-Pacific Journal of Chemical Engineering, 2014; 9(6): 866-876.

[16] Alfaro-Ayala J A, Ayala-Ram R V, Gallegos-Mu O A, Uribe-Ramirez A R. Optimal location of axial impellers in a stirred tank applying evolutionary programing and CFD. Chemical Engineering Research and Design, 2015; 100: 203-211.

[17] Bonnot S, Cabaret F, Fradette L, Tanguy P A. Characterization of Mixing Patterns in a Coaxial Mixer. Chemical Engineering Research and Design, 2007; 85(8): 1129-1135.

[18] Couerbe G, Fletcher D F, Xuereb C, Poux M. Impact of thixotropy on flow patterns induced in a stirred tank: Numerical and experimental studies.
Chemical Engineering Research \& Design, 2008; 86(6A): 545-553.

[19] Zadghaffari R, Moghaddas J S, Revstedt J. A mixing study in a double-Rushton stirred tank. Computers \& Chemical Engineering, 2009; 33(7): 1240-1246

[20] Holman J P. Heat Transfer ( $9^{\text {th }}$ edition). London: MaGraw-Hill, 2001.

[21] Achouri R, Mokni I, Mhiri H, Bournot P. A 3D CFD simulation of a self inducing Pitched Blade Turbine Downflow. Energy Conversion and Management, 2012; 64: 633-641.

[22] Sack J R, Urrutia J. Handbook of Computational Geometry. Amsterdam: Elsevier Science, 2000.

[23] Qi N, Zhang H, Zhang K, Xu G, Yang Y P. CFD simulation of particle suspension in a stirred tank. Particuology, 2013; 11(3): 317-26.

[24] Ascanio G. Mixing time in stirred vessels: A review of experimental technique. Chinese Journal of Chemical Engineering, 2015; 23(7): 1065-76.

[25] Roy R K. Design of experiments using the Taguchi approach: 16 steps to product and process improvement. New York: John Willey and Sons Inc. 2001. 